\title{
Association of Human Q Fever with Animal Husbandry, Taiwan, 2004-2012
}

\author{
Chung-Hsu Lai, Lin-Li Chang, Jiun-Nong Lin, \\ Ming-Huei Liao, Shyh-Shyan Liu, Hsu-Hsun Lee, \\ Hsi-Hsun Lin, Yen-Hsu Chen
}

In Taiwan, Q fever cases in humans began increasing in 2004 and peaked in 2007 but dramatically declined in 2008 and 2011. Cases were significantly correlated with the number of goats. The decline might be associated with the collateral effects of measures to control goat pox in 2008 and 2010.

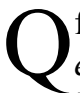
fever is a zoonosis caused by infection with Coxiella burnetii, a gram-negative bacterium and obligate intracellular pathogen. The major animal reservoirs are goats, sheep, and cattle. Humans are infected mainly through inhalation of aerosolized particles contaminated with $C$. burnetii excreted by an infected animal, particularly in fetal products, milk, urine, and feces (1). Nearly $60 \%$ of primary infections (acute $\mathrm{Q}$ fever) are asymptomatic. Symptomatic infection is characterized by influenzalike symptoms, occasionally accompanied by hepatitis or pneumonia.

Historically, the largest outbreak of Q fever caused nearly 4,000 human infections in the Netherlands during 2007-2010 (2). Epidemiologic studies implicated infected farm animals (sheep and goats) as the source for human infection $(2,3)$. In the United States, an outbreak was associated with fetal products from aborted goats (4). Because of improved recognition and reporting of Q fever, it became reportable in the United States in 1999, and the number of cases increased by $250 \%$ during 2000-2004 (5).

In Taiwan, $\mathrm{Q}$ fever is endemic, particularly in the south (6). We previously identified the epidemiology and clinical characteristics of $\mathrm{Q}$ fever in Taiwan, but the association between human $\mathrm{Q}$ fever and animal husbandry has not been investigated (7-9). Our objective was to investigate the epidemiology of human $\mathrm{Q}$ fever and its association with animals by analyzing nationwide databases of human Q fever and animal husbandry during 2004-2012.

Author affiliations: Kaohsiung Medical University, Kaohsiung

City, Taiwan (C.-H. Lai, L.-L. Chang, J.-N. Lin, Y.-H. Chen);

E-Da Hospital/I-Shou University, Kaohsiung City (C.-H. Lai, J.-N. Lin, H.-H. Lin); National Pingtung University of Science and Technology, Neipu, Taiwan (M.-H. Liao, S.-S. Liu, H.-H. Lee); National Yang-Ming University, Taipei City, Taiwan $(\mathrm{H} .-\mathrm{H}$. Lin): National Chiao Tung University, HsinChu, Taiwan (Y.-H, Chen)

DOI: http://dx.doi.org/10.3201/eid2112.141997

\section{The Study}

The Ethics Committee of E-Da Hospital (EMRP-103042) approved this study. We collected data on confirmed human $\mathrm{Q}$ fever cases in Taiwan that occurred during 2004-2012 from the notifiable infectious diseases statistics system established by the Centers for Disease Control and Prevention of Taiwan (Taiwan CDC), which is an open and public website (http://nidss.cdc.gov.tw/ch/ SingleDisease $. \operatorname{asp} x ? \mathrm{dc}=1 \& \mathrm{dt}=4 \&$ disease $=0830$ ). The data included the number of confirmed cases, patient sex, age groups (5-year groups), and the geographic locations of cases (county and district) in Taiwan every month from 2004 through 2012. Reported cases included suspected cases of Q fever reported to the Taiwan CDC by clinicians. Generally, paired blood specimens (acute or convalescent phase) from reported case-patients are collected and sent to the contracted laboratories of the Taiwan CDC for laboratory testing of $\mathrm{Q}$ fever. Confirmed cases are reported cases that are confirmed positive for Q fever by laboratory tests. Q fever was confirmed either by serologic detection of $\mathrm{a} \geq 4$-fold increase in specific antibodies against $C$. burnetii phase II antigen by using an indirect immunofluorescence antibody assay or by a molecular method consisting of positive detection of $C$. burnetii DNA in blood using PCR.

We collected husbandry data on goats and cattle from 2004 through 2012 from the open and publicly available data released by the Council of Agriculture, Executive Yuan, Taiwan (http://agrstat.coa.gov.tw/sdweb/public/official/OfficialInformation.aspx). The maps of the geographic distributions of $\mathrm{Q}$ fever cases and animals were created by using SuperGIS Desktop software (Supergeo Technologies Inc., Taipei, Taiwan).

We identified $879(6.3 \%)$ confirmed cases of Q fever among the 13,962 cases reported during 2004-2012. The number of confirmed cases increased dramatically starting in 2004 and peaked in 2007 but declined in 2008 and 2011 (Figure 1, panel A). Additionally, the annual incidence increased from 0.44 cases per 100,000 population in 2004 to 0.68 in 2007 and decreased from 0.40 in 2008 to 0.15 in 2011 . Overall average annual incidence was 0.43 cases per 100,000 population. Cases occurred mainly in southern Taiwan (674 [76.7\%] of 879) and particularly in the southern (17.4\%) and Kaohsiung-Pingtung (59.3\%) regions (Figure 1, panels A, B), and were most prevalent from March through September (669 [76.1\%] cases) (Figure 1, panel C). Most case-patients were 30-69 

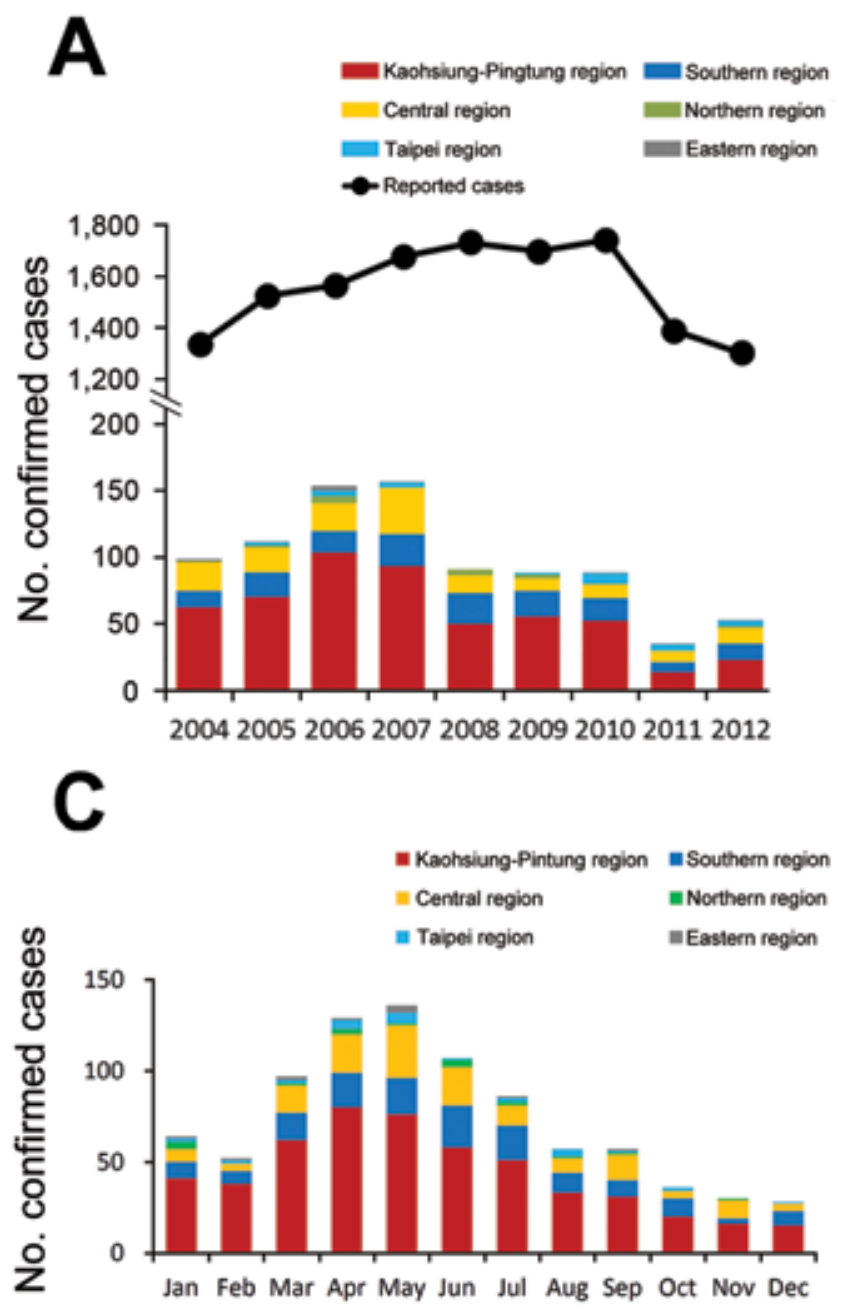

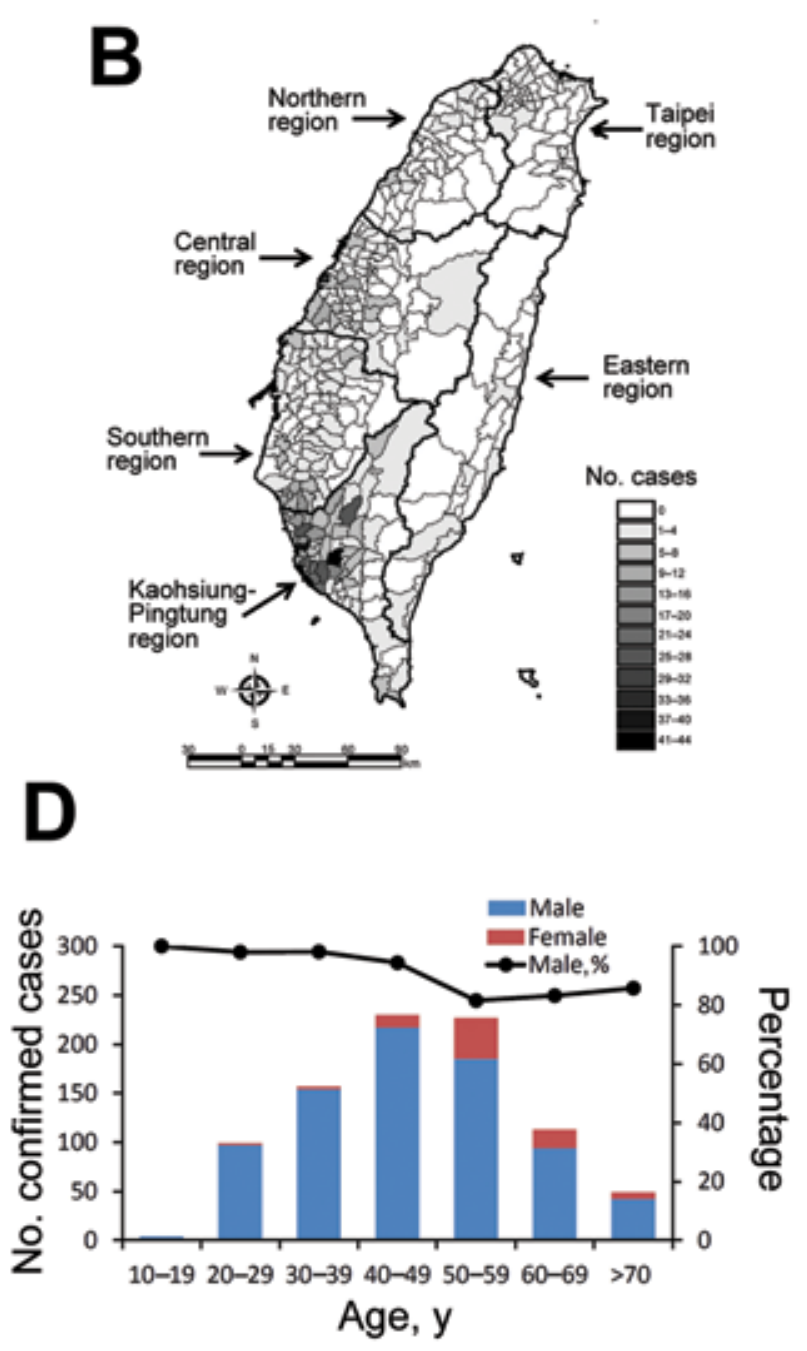

Age, $y$

Figure 1. Q fever in humans, Taiwan, 2004-2012. A) Trends in reported and confirmed cases of Q fever. B) Geographic distribution of confirmed cases of $Q$ fever. C) Monthly distribution of the confirmed cases. D) Age and sex distributions of patients with confirmed $Q$ fever.

years old $(727[82.7 \%])$ and male $(793[90.2 \%])$ (Figure 1 , panel D).

During 2004-2014, cattle and goats were distributed primarily in the southern and Kaohsiung-Pingtung regions (Figure 2, panels A, C). The trend of human Q fever cases was significantly correlated with the number of goats, rather than with the number of cattle (Figure 2, panels B, D).

\section{Conclusions}

During 2004-2012, the average incidence of Q fever in Taiwan was 0.43 cases per 100,000 population, which was higher than the incidence in the United States (0.04) (10) but lower than that in France (2.5) (11). Regardless of these differences in incidence, Q fever cases increased after Q fever became notifiable in the United States $(5,10)$ and France (11). This increase might be attributed to improved recognition and increased reporting of notifiable infectious diseases to the authorities. In Taiwan, we have previously illustrated that reported and confirmed Q fever cases dramatically increased beginning in 2004, 3 years before it became notifiable in October 2007 (6). However, confirmed cases of Q fever decreased in 2008, even though the number of reported cases remained steady during 2007-2010 (Figure 1, panel A). Accordingly, the changing number of confirmed cases could not be explained by a change in the number of reported cases or by the advent of $\mathrm{Q}$ fever as a notifiable disease in Taiwan.

Most cases occurred in southern Taiwan, particularly in the Kaohsiung-Pingtung region, despite fluctuations in the yearly number of cases (Figure 1, panels A, B). Geographic distribution was correlated with the distribution of cattle and goat husbandry, which was predominant in southern Taiwan (Figure 2, panels A, C). A serologic study in the Kaohsiung-Pingtung region found a high seroprevalence of $\mathrm{Q}$ fever in animals (12). Seroprevalence rates in the overall herd and in individual animals were, respectively, 

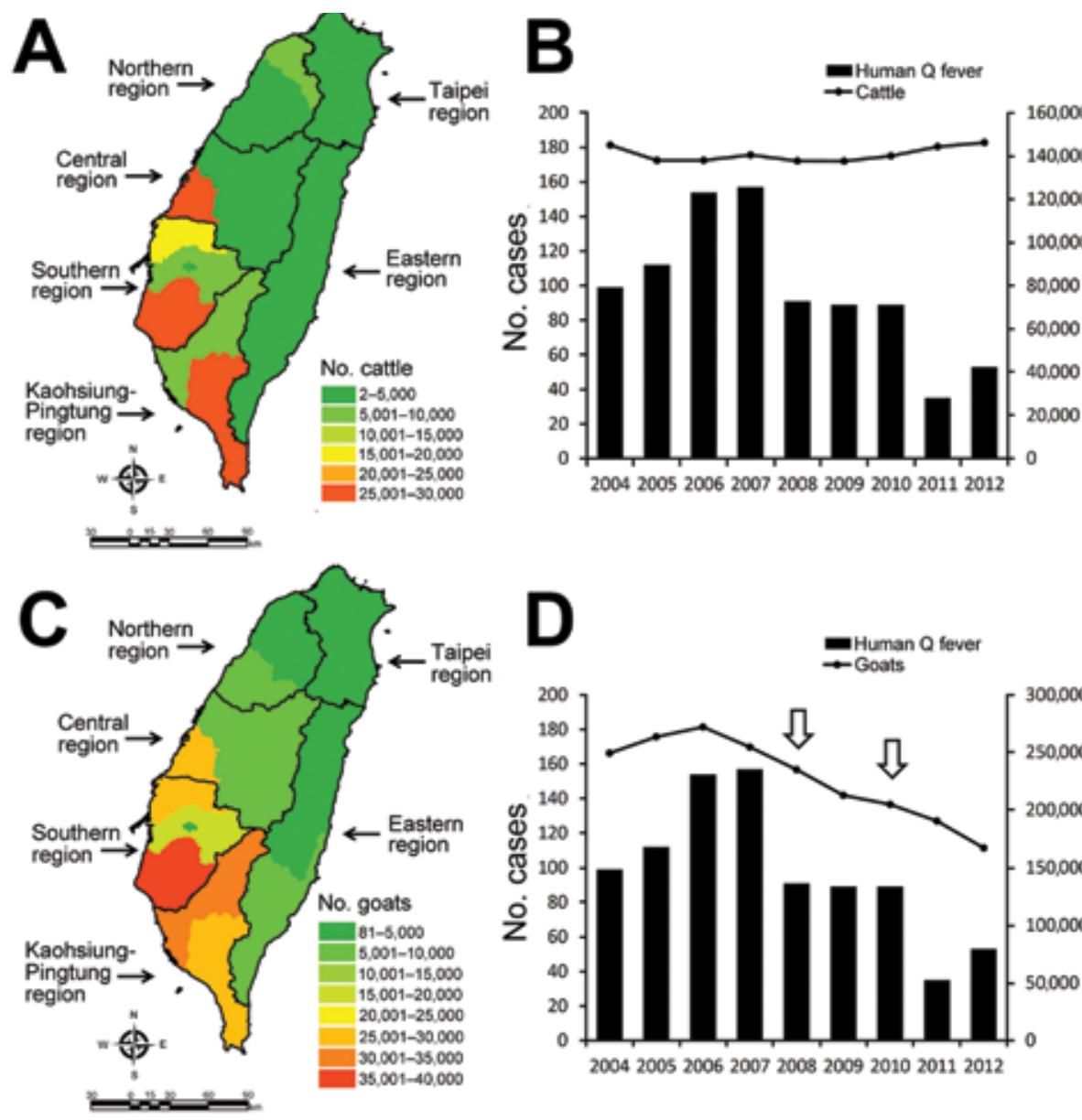

Figure 2. $Q$ fever in cattle and goats and comparison with number of human $Q$ fever cases, Taiwan, 2004-2012. A) Average number and distribution of cattle during 2004-2012; B) comparison of $Z$ human $Q$ fever cases and number of cattle showing no correlation ( $p=0.123)$. C) Average number and distribution of goats during 2004-2012; D) comparison of human $Q$ fever cases and the number of goats showing a significant correlation $(p=0.003)$. Arrows indicate goat pox epidemics of 2008 and 2010. The correlation between human $Q$ fever, cattle, and goat was analyzed by

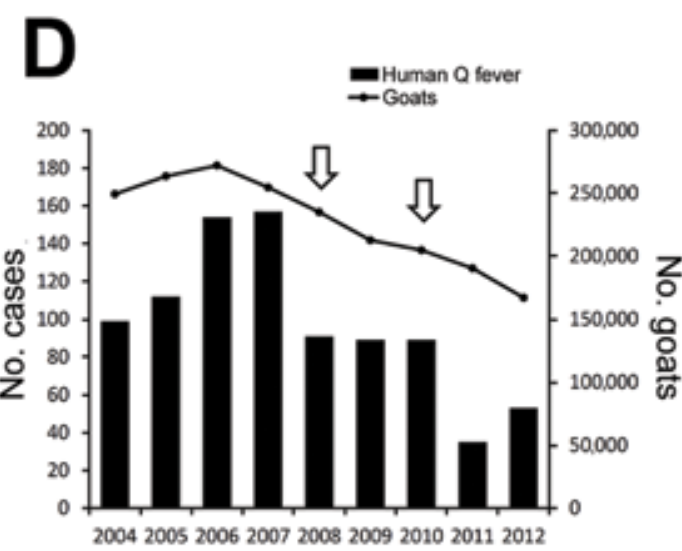
Pearson's correlation.

$73.6 \%$ and $48.3 \%$ in goats and $66.7 \%$ and $19.5 \%$ in cattle. In addition, the $26.3 \%$ seroprevalence in persons engaging in veterinary and animal-related work was higher than in the reference population $(2.7 \%)$. Thus, we suspected that the decrease in the number of human cases might have been associated with animal reservoirs, particularly goats.

Goats and cattle are the major animal reservoirs of C. burnetii. We illustrated that the increase and decrease in human Q fever cases was correlated with variation in the number of goats, rather than cattle (Figure 2, panel B). After the number of goats began to decrease in 2007, human Q fever cases dramatically decreased in 2008 and 2011. The decrease in the number of goats was possibly associated with 2 episodes of goat pox epidemics in July 2008 and April 2010 (Figure 2, panel D) and the culling of 210 and $>20,000$ goats in the 2008 and 2010 epidemics, respectively $(13,14)$. To control the goat pox epidemics, several measures were enacted, including animal and vehicle movement control within infected areas, cleaning and disinfection of infected farms and equipment, culling of infected animals, and vaccination. Although these measures were applied to control goat pox, collateral effects that diminished the spread of $C$. burnetii from infected goats or a contaminated environment to humans also might have existed.

This study has certain limitations. The association between livestock numbers and human $\mathrm{Q}$ fever might be ecologic because data on individual exposures and on Q fever in goats and cattle over time were not available for analysis.

In conclusion, Q fever is an endemic disease in Taiwan. Human cases increased beginning in 2004 and decreased in 2008 and 2011, which was correlated with the number of goats and possibly was associated with the collateral effects of measures taken to control goat pox in 2008 and 2010.

This work was supported by a research grant from E-Da Hospital (EDAHP103001) and the Ministry of Science and Technology (MOST 103-2314-B-650-008). The funders had no role in the study design, data collection and analysis, decision to publish, or manuscript preparation.

Dr. Lai is an infectious disease specialist at E-Da Hospital in Kaohsiung City, Taiwan. His research interests include rickettsioses, antimicrobial drug resistance, and the epidemiology of nosocomial pathogens. 


\section{References}

1. Maurin M, Raoult D. Q fever. Clin Microbiol Rev. 1999;12:518-53.

2. Dijkstra F, van der Hoek W, Wijers N, Schimmer B, Rietveld A, Wijkmans CJ, et al. The 2007-2010 Q fever epidemic in the Netherlands: characteristics of notified acute $\mathrm{Q}$ fever patients and the association with dairy goat farming. FEMS Immunol Med Microbiol. 2012;64:3-12. http://dx.doi.org/10.1111/j.1574-695X.2011.00876.x

3. Roest HI, Tilburg JJ, van der Hoek W, Vellema P, van Zijderveld FG, Klaassen $\mathrm{CH}$, et al. The $\mathrm{Q}$ fever epidemic in the Netherlands: history, onset, response and reflection. Epidemiol Infect. 2011;139:1-12. http://dx.doi.org/10.1017/S0950268810002268

4. Bjork A, Marsden-Haug N, Nett RJ, Kersh GJ, Nicholson W, Gibson D, et al. First reported multistate human Q fever outbreak in the United States, 2011. Vector Borne Zoonotic Dis. 2014;14:111-7. http://dx.doi.org/10.1089/vbz.2012.1202

5. McQuiston JH, Holman RC, McCall CL, Childs JE, Swerdlow DL, Thompson HA. National surveillance and the epidemiology of human Q fever in the United States, 1978-2004. Am J Trop Med Hyg. 2006;75:36-40.

6. Lai CH, Huang CK, Chin C, Chung HC, Huang WS, Lin CW, et al. Acute Q fever: an emerging and endemic disease in southern Taiwan. Scand J Infect Dis. 2008;40:105-10. http://dx.doi.org/ $10.1080 / 00365540701558722$

7. Lai CH, Chin C, Chung HC, Huang CK, Chen WF, Yang YT, et al. Acute $\mathrm{Q}$ fever hepatitis in patients with and without underlying hepatitis B or C virus infection. Clin Infect Dis. 2007;45:e52-9. http://dx.doi.org/10.1086/520680

8. Lai CH, Huang CK, Chen YH, Chang LL, Weng HC, Lin JN, et al. Epidemiology of acute $\mathrm{Q}$ fever, scrub typhus, and murine typhus, and identification of their clinical characteristics compared to patients with acute febrile illness in southern taiwan. J Formos Med
Assoc. 2009;108:367-76. http://dx.doi.org/10.1016/ S0929-6646(09)60080-2

9. Lai CH, Chang LL, Lin JN, Chen WF, Wei YF, Chiu CT, et al. Clinical characteristics of $\mathrm{Q}$ fever and etiology of communityacquired pneumonia in a tropical region of southern Taiwan: a prospective observational study. PLoS ONE. 2014;9:e102808. http://dx.doi.org/10.1371/journal.pone.0102808

10. Dahlgren FS, McQuiston JH, Massung RF, Anderson AD. Q fever in the United States: summary of case reports from two national surveillance systems, 2000-2012. Am J Trop Med Hyg. 2015;92:247-55. http://dx.doi.org/10.4269/ajtmh.14-0503

11. Frankel D, Richet H, Renvoise A, Raoult D. Q fever in France, 1985-2009. Emerg Infect Dis. 2011;17:350-6. http://dx.doi.org/ 10.3201/eid1703.100882

12. Chang CC, Lin PS, Hou MY, Lin CC, Hung MN, Wu TM, et al. Identification of risk factors of Coxiella burnetii (Q fever) infection in veterinary-associated populations in southern Taiwan. Zoonoses Public Health. 2010;57:e95-101. http://dx.doi.org/10.1111/ j.1863-2378.2009.01290.x

13. Focus Taiwan, Central News Agency. Sheep pox \& goat pox, caprine-Taiwan. ProMed. 2010 May 30.

http://www.promedmail.org, archive no. 20100530.1796.

14. Hsieh YC, Tsai KY, Hung CN, Ou CM, Huang JY, Tsai SS. Pathological and molecular studies on goat pox [in Chinese]. Taiwan Vet J. 2010;36:315-23.

Address for correspondence: Yen-Hsu Chen, Kaohsiung Medical University Hospital, Kaohsiung Medical University; National Chiao Tung University; Taiwan-Department of Infectious Diseases, 100, Tzyou 1st Rd, Kaohsiung 807, Taiwan; email: infchen@gmail.com

\section{April 2015: Emerging Viruses}

Including:

- Reappearance of Chikungunya, Formerly Called Dengue, in the Americas

- Hantavirus Pulmonary Syndrome, Southern Chile, 1995-2012

- Animal-Associated Exposure to Rabies Virus among Travelers, 1997-2012

- Evolution of Ebola Virus Disease from Exotic Infection to Global Health Priority, Liberia, Mid-2014

- Population Structure and Antimicrobial Resistance of Invasive Serotype IV Group B Streptococcus, Toronto, Ontario, Canada

- Norovirus Genotype Profiles Associated with Foodborne Transmission, 1999-2012

- Deaths Associated with Respiratory Syncytial and Influenza Viruses among Persons $>5$ Years of Age in HIV-Prevalent Area, South Africa

- Sequence Variability and Geographic Distribution of Lassa Virus, Sierra Leone

- Influenza A(H7N9) Virus Transmission between Finches and Poultry

- Highly Pathogenic Avian Influenza A(H5N1) Virus Infection among Workers at Live Bird Markets, Bangladesh, 2009-2010

\section{http://wwwnc.cdc.gov/eid/articles/ EMERING} issue/2 1/4/table-of-contents 